\title{
Angiosarcoma Presenting with Spontaneous Hydropneumothorax: Report of a Case and Review of the Literature
}

\author{
Jung H. Chang ${ }^{*}, 1$, Ji H. Kim ${ }^{1}$, So-Hyeon Hong ${ }^{1}$, Myung E. Song ${ }^{1}$, Yon J. Ryu ${ }^{1}$, \\ Jin H. Lee ${ }^{1}$, Sung S. Shim ${ }^{2}$, Min-Sun $\mathrm{Cho}^{3}$ and Yun S. Sim ${ }^{4}$
}

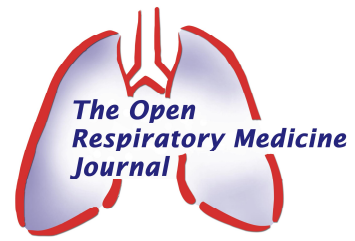

\author{
${ }^{I}$ Division of Pulmonary and Critical Care Medicine, Department of Medicine, ${ }^{2}$ Department of Radiology and \\ ${ }^{3}$ Pathology, School of Medicine, Ewha Womans University, Seoul, South Korea; ${ }^{4}$ Division of Pulmonary, Allergy and \\ Critical Care Medicine, Department of Internal Medicine, Hallym University Kangnam Sacred Heart Hospital, Seoul, \\ South Korea
}

\begin{abstract}
Angiosarcoma is a rare malignant tumor of soft tissue. Because angiosarcoma originates from endothelial cells, it can occur in any organ and shows aggressive clinical features. Most commonly, angiosarcoma initially presents as a cutaneous lesion. Lung metastasis from scalp angiosarcoma can develop pneumothorax. We report a case of multiorgan involvement of an angiosarcoma, including the scalp, initially presenting with hydropneumothorax. Immunohistochemistry analysis of the cells obtained from the study confirmed the pleural invasion of the angiosarcoma.
\end{abstract}

Keywords: Angiosarcoma, hydropneumothorax, immunohistochemistry, scalp.

\section{INTRODUCTION}

Angiosarcoma is a rare aggressive malignancy that has a poor prognosis despite current intensive treatment [1-3]. This tumor can involve multiple organs, including the pleura. Pneumothorax is known to develop from spontaneous rupture of cystic lung lesions in angiosarcoma [4]. In a case of pleural effusion of angiosarcoma, cytology is often negative pathologically under routine stains, and specific immunohistochemical stains can be confirmative $[5,6]$. We report a case of angiosarcoma involving the heart, lungs, lymph nodes, scalp, and liver, with malignant pleural effusion.

\section{CASE REPORT}

An 83-year-old male visited a local clinic because of sudden chest pain, which developed 1 month prior and became aggravated 1 week previously. He was referred to our hospital for the problem of hydropneumothorax. There was no specific history or familial history of cancer, diabetes, or tuberculosis. He had a 25 pack-year of smoking history. On admission, he appeared acutely ill. His blood pressure was $110 / 70 \mathrm{mmHg}$, his pulse rate was 100 beats per minute, and his body temperature was $36.6^{\circ} \mathrm{C}$. He showed a poor performance status with an Eastern Cooperative Oncology Group (ECOG) scale score of 3. A mass was palpated on the left supraclavicular area, and it was not

*Address correspondence to this author at the Division of Pulmonary and Critical Care Medicine, Department of Medicine, School of Medicine, Ewha Womans University, Anyangcheon-Ro 1071, Yangcheon-gu, Seoul, 158710, South Korea; Tel : +82-2-2650-5686; Fax: +82-2-2655-2076; E-mail: hs1017@ewha.ac.kr tender and firm in consistency. There was a skin lesion of $6 \mathrm{~mm}$ in size that was not painful and that was violet and dome shaped in elevation on the left parietal lobe of the skull. Breathing sounds in the left lower lung field were decreased, and no crackles were heard. Other physical findings were negative. On the day of admission, his white blood cell count was $10,400 / \mathrm{mm}^{3}$ with $70 \%$ neutrophils and $25 \%$ lymphocytes, the hemoglobin level was $12.5 \mathrm{~g} / \mathrm{dL}$, and the platelet count was $269,000 / \mathrm{mm}^{3}$. Serum biochemical values were as follows: the blood urea nitrogen level was 23 $\mathrm{mg} / \mathrm{dL}$, the creatinine level was $1.6 \mathrm{mg} / \mathrm{dL}$, the total protein level was $5.0 \mathrm{mg} / \mathrm{dL}$, the albumin level was $2.6 \mathrm{mg} / \mathrm{dL}$, and other values were within normal ranges. The levels of neuron-specific enolase, carcinoembryonic antigen, alpha fetoprotein, and CA $19-9$ were $14.1 \mathrm{ng} / \mathrm{mL}, 3.6 \mathrm{ng} / \mathrm{mL}, 1.9$ $\mathrm{ng} / \mathrm{mL}$, and $7.5 \mathrm{U} / \mathrm{mL}$, respectively. Initial pleural fluid analysis showed a $\mathrm{pH}$ of 7.2, the white blood cell count was $6500 / \mathrm{mm}^{3}$ with $90 \%$ eosinophils, $7 \%$ lymphocytes, and $1 \%$ neutrophils, the total protein level was $3.3 \mathrm{mg} / \mathrm{dL}$, the albumin level was $2.0 \mathrm{mg} / \mathrm{dL}$, the lactic dehydrogenase level was $356 \mathrm{U} / \mathrm{L}$, the adenosine-deaminase level was $29.4 \mathrm{U} / \mathrm{L}$, and the carcinoembryonic antigen level was $6.1 \mathrm{ng} / \mathrm{mL}$. Results for microbiology and cytology in the pleural fluid were negative. On the day of admission, chest radiography showed the finding of hydropneumothorax (Fig. 1). Chest computed tomography (CT) showed multiple tiny nodules and cystic lesions on both lungs, a large amount of pleural effusion with pneumothorax in the left lung, pericardial effusion, enlargement of multiple lymph nodes, and multiple hepatic masses (Fig. 2). Trans-thoracic echocardiography showed a mass with a diameter of $2.0 \mathrm{~cm}$ at the right atrioventricular orifice (Fig. 3). Because initial pleural fluid cytology was reported to be negative, excisional biopsy of 


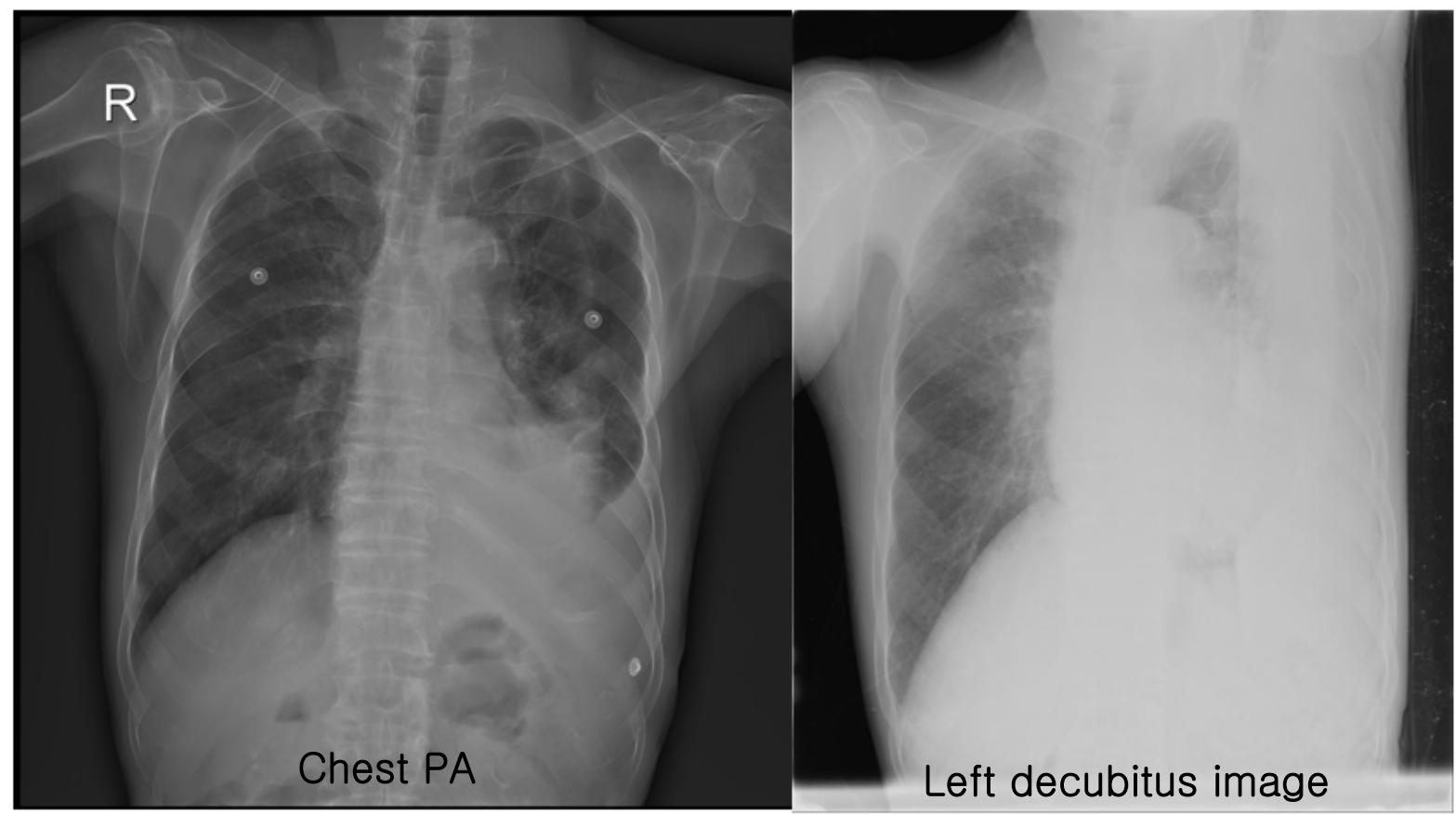

Fig. (1). Posterioranterior chest radiography and left decubitus film on admission show hydropneumothorax on the left side.

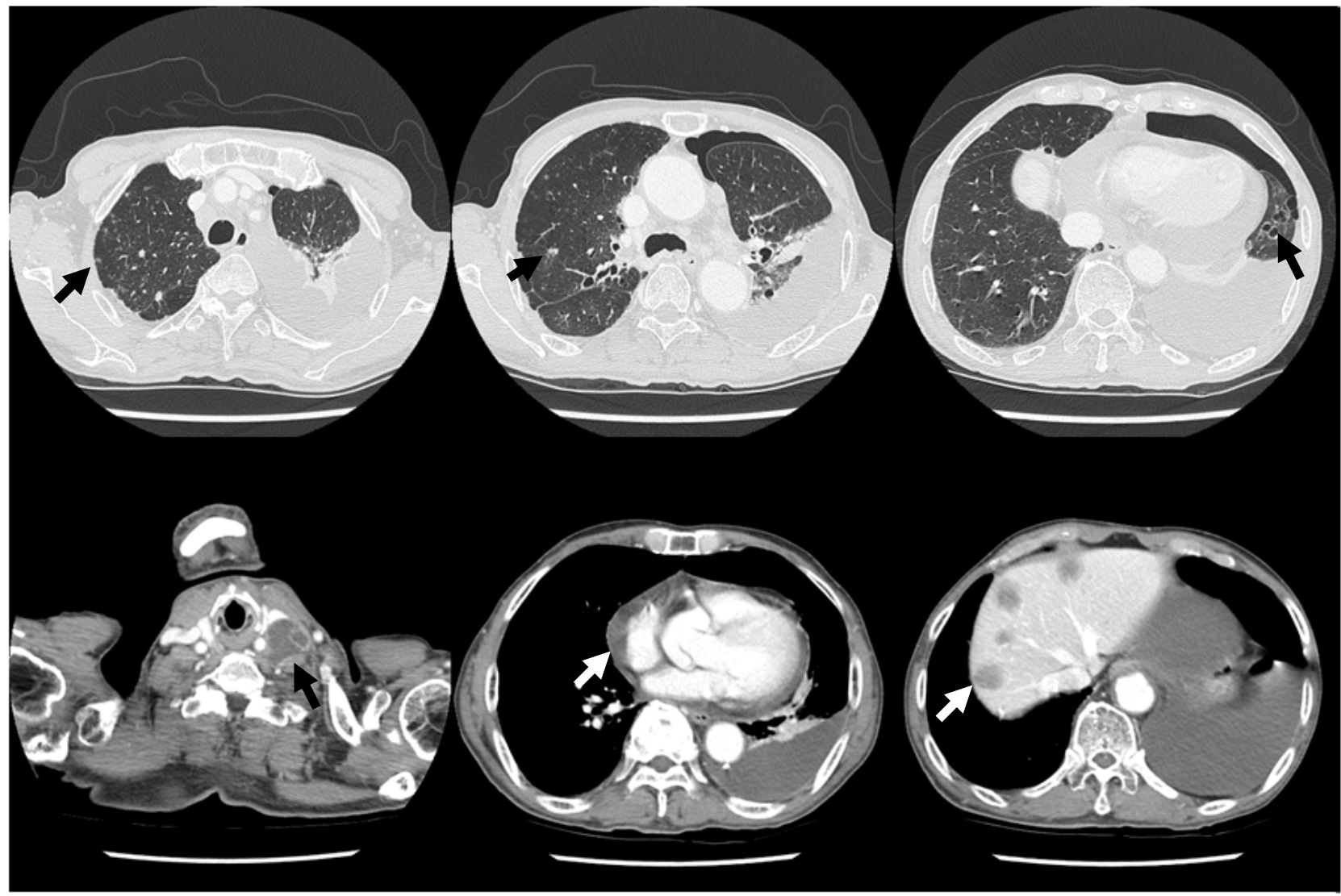

Fig. (2). Computed tomography shows multiple tiny nodules and cystic lesions on both lungs, a large amount of left pleural effusion with pneumothorax, pericardial effusion, enlargement of multiple lymph nodes, and multiple hepatic masses.

the cervical lymph nodes was performed. Histopathology revealed that the lymph nodes were almost replaced by the tumor, which formed an anastomosing network of sinusoids lined by hyperchromatic nucleated endothelial cells (Fig. 4). Positron emission tomography-CT showed a standardized uptake value of 14.3 on fluorodeoxyglucose uptake at the left tonsil and also increased uptake at cervical lymph nodes, both lungs, and the liver (Fig. 5). A second thoracentesis revealed pleural metastasis of angiosarcoma under the stains of CD31, CD34, and von Willebrand factor for the atypical 


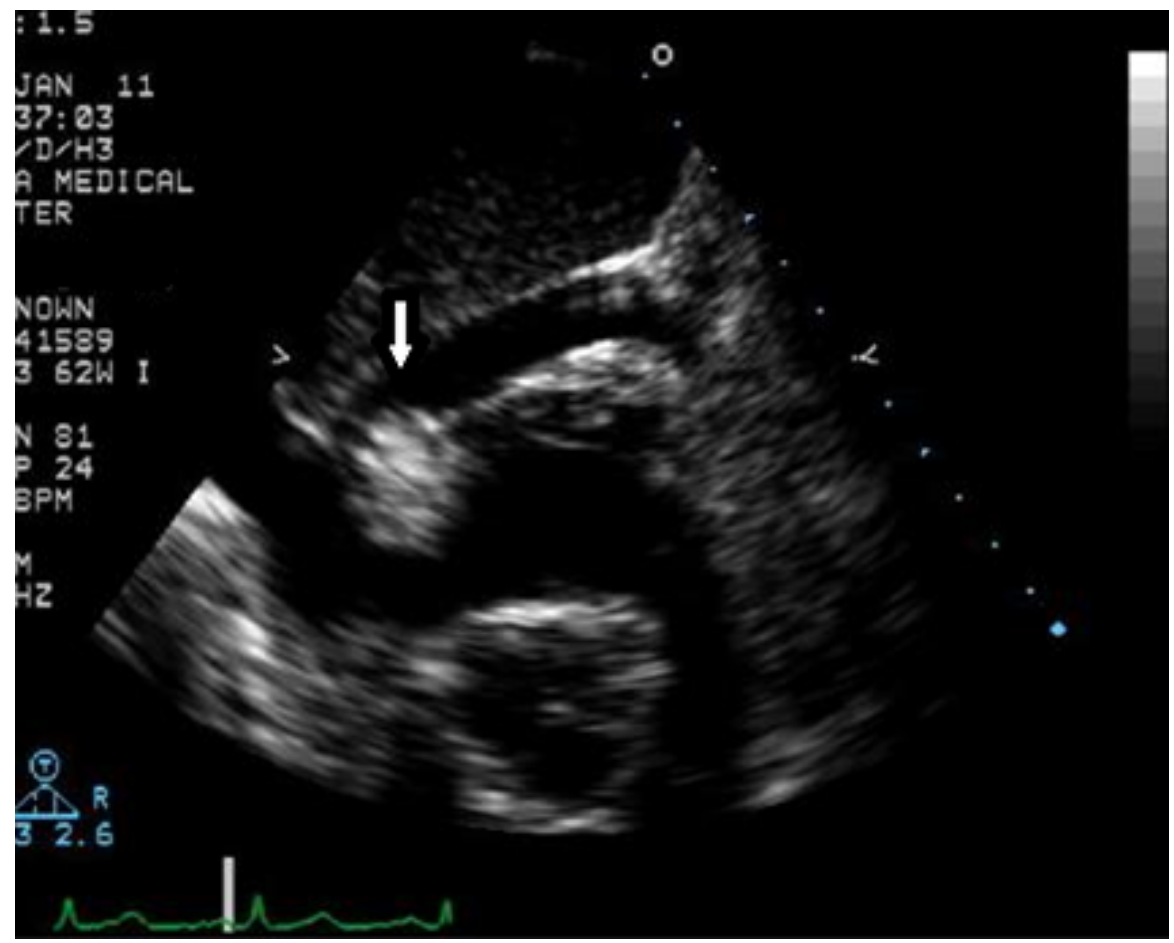

Fig. (3). Echocardiography shows a mass with a diameter of $2.0 \mathrm{~cm}$ at the right atrioventricular orifice.

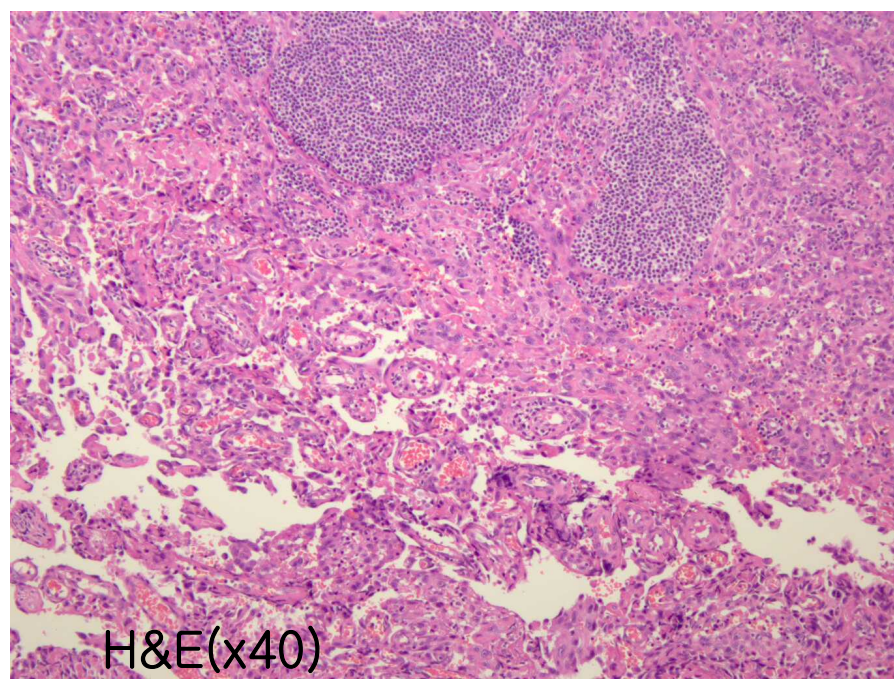

(A)

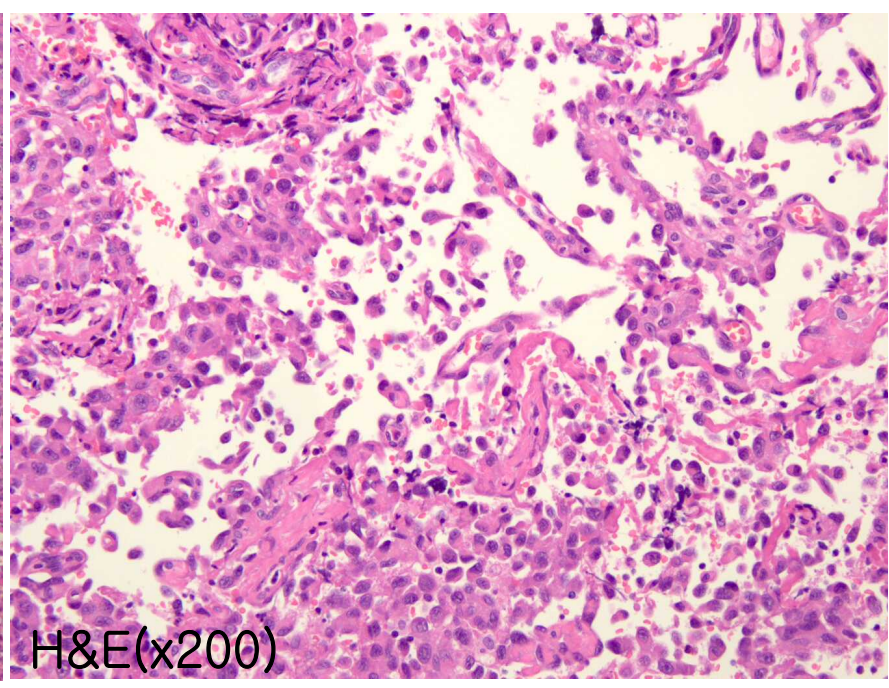

(B)

Fig. (4). Histological findings of cervical lymph nodes. (A) Lymph nodes are almost replaced by angiosarcoma, which forms an anastomosing network of sinusoids, lined by hyperchromatic, nucleated endothelial cells (hematoxylin and eosin $(\mathrm{H} \& \mathrm{E})$ staining, $\times 40) .(\mathbf{B})$ A distinct sinusoid pattern with malignant endothelial cells, some of which are scattered in the lumen of sinusoids, is seen (H\&E stain, $\times$ 200).

cell cluster of the pleural fluid (Fig. 6). Because of the involvement of angiosarcoma in the heart, lungs, pleura, multiple lymph nodes, skin, and liver, the patient was discharged after conservative treatment with consideration of age and current performance status.

\section{DISCUSSION}

Angiosarcoma is a malignant cancer that rarely occurs and has a poor prognosis. Angiosarcoma occurs at a male predominance, and mostly affects elderly people, although it can occur at all ages. We reviewed 33 patients from 24 previous reports concerning angiosarcoma with pneumothorax that were based on a PubMed search since 1978. Among the 33 subjects, 21 cases were available for review; 16 subjects were male and 5 were female. The mean age was 68 years, and the most common computed tomography findings were multiple thin-walled cysts and nodules located in the subpleural area (Table 1). As a spontaneous pneumothorax in an aged person, the differential diagnosis was most commonly emphysema $(91 \%)$, followed by isolated bulla or blebs $(4 \%)$, 


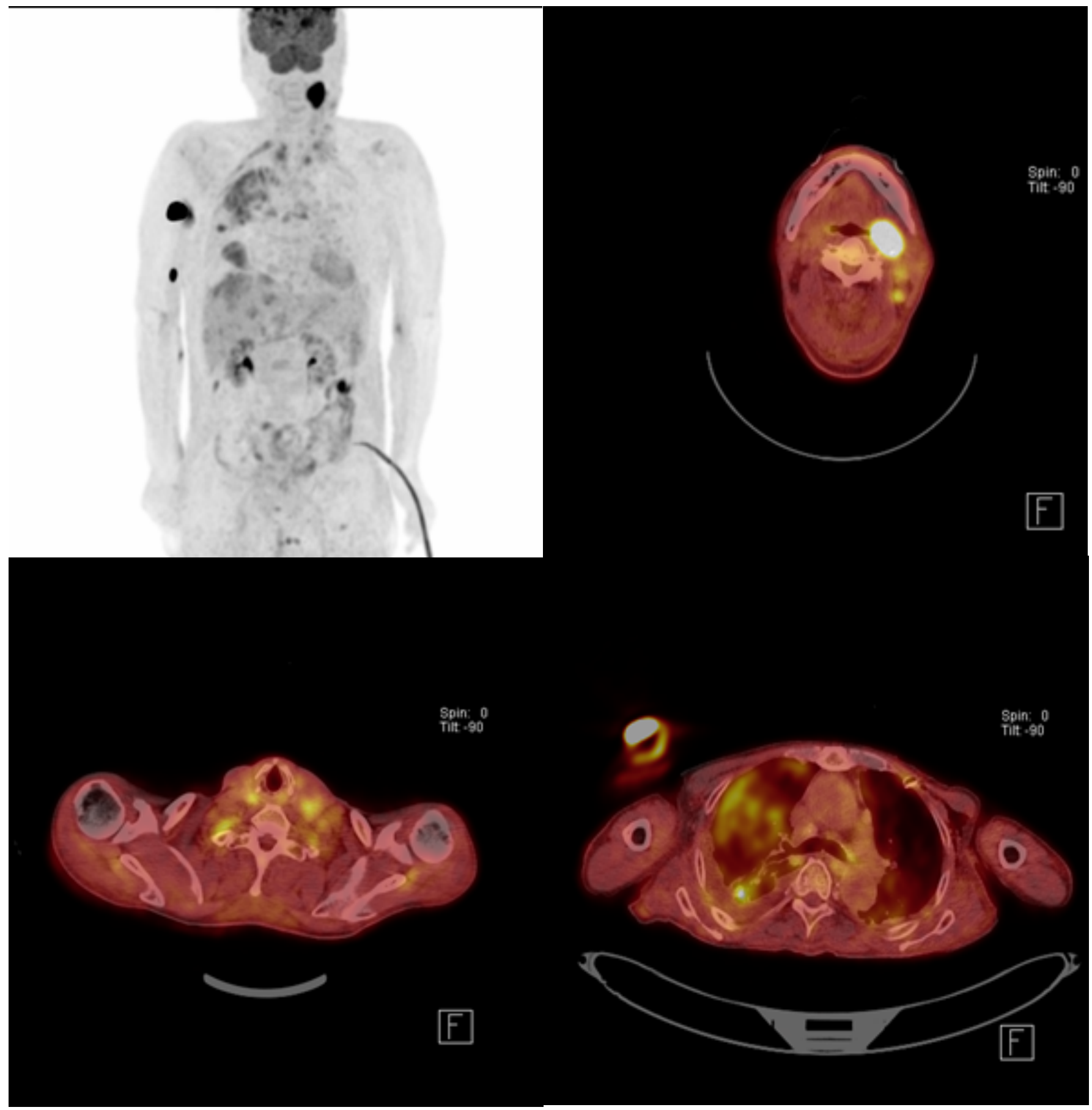

Fig. (5). Positron emission tomography-CT shows a standardized uptake value of 14.3 on fluorodeoxyglucose uptake at the left tonsil and also increased uptake at cervical lymph nodes, both lungs, and the liver.

mesothelioma $(2 \%)$, and rare cases of subpleural fibrosis, congenital cystic adenomatoid malformation, tuberculous pleuritis, and angiosarcoma [7].

Radiation therapy is a risk factor for angiosarcoma. In addition, vinyl chloride, thorium dioxide, arsenic, anabolic steroids, neurofibromatosis, Maffucci syndrome, and Klippel-Trenaunay syndrome are known to be risk factors [8-10].

There have been higher diagnostic yields over the years from the development of diagnostic technology, such as pathological technology $[8,9]$. Angiosarcoma as an angiogenic tumor can have a definite diagnosis by confirming vascular markers by immunochemistry. Endothelium-specific immune markers include CD31, CD34, and von Willebrand factor. Von Willebrand factor shows high specificity with relatively low sensitivity, while CD34 and CD31 show high specificity and sensitivity $[6,11]$.

Angiosarcoma occurs at various locations, most commonly at the head and neck, breast, limbs and trunk [8, 9]. With multiple organ involvement at the time of diagnosis, it can be difficult to conclude which area is the primary site. However, regarding pneumothorax, the scalp was the most 


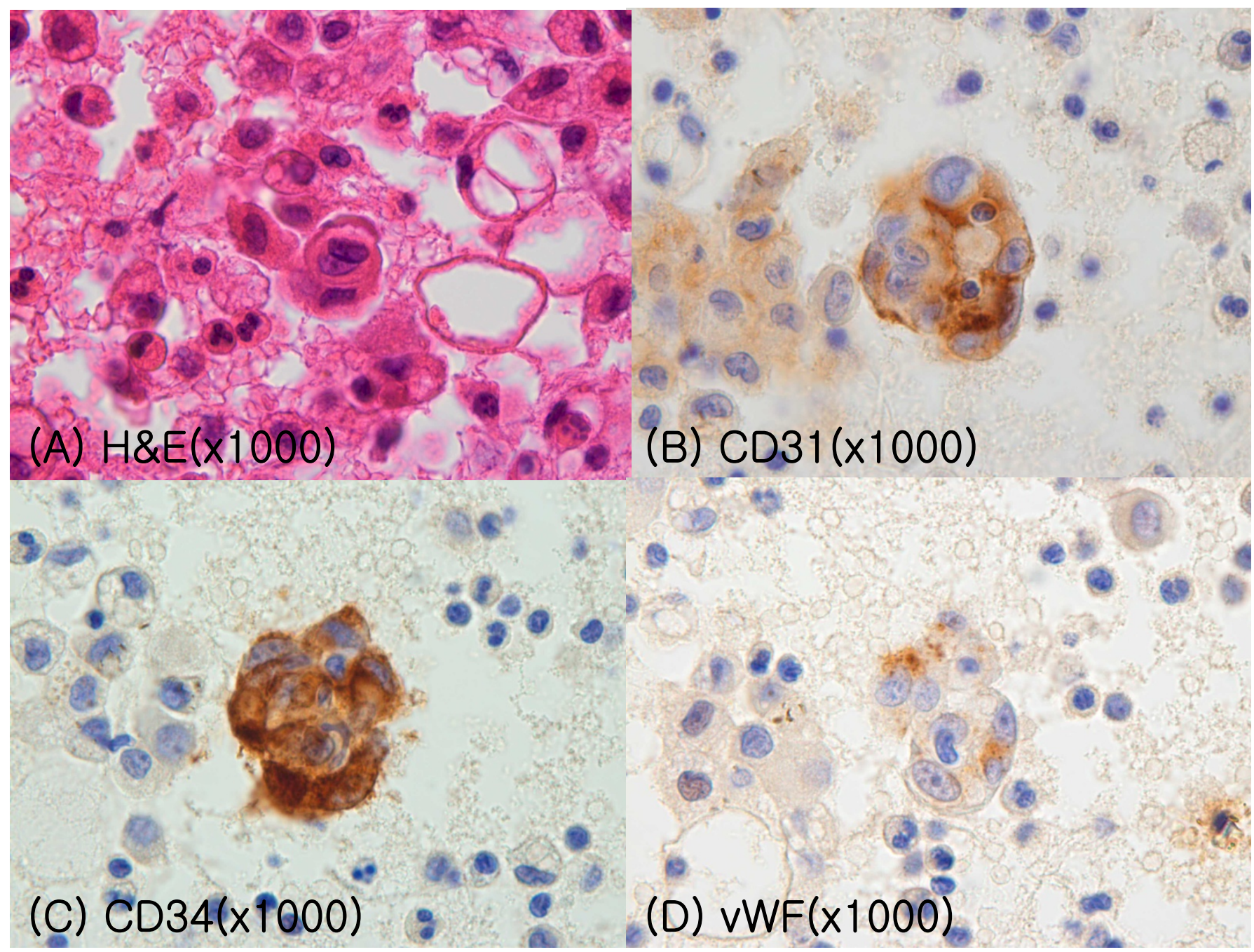

Fig. (6). Pathological findings of pleural fluid cytology. (A) H\&E staining. (B-D) Immunohistochemical staining of an atypical cell cluster: (B) CD31, (C) CD34, and (D) von Willebrand factor $(\times 1000)$.

common primary site of angiosarcoma [12]. This was true in our case, as well as in literature reviews (Table 1). When angiosarcoma invades the lungs, pneumothorax or hemothorax results by forming nodular lesions or a cystic change [13]. Although there is no well-established treatment or prospective study results for angiosarcoma, radiation and surgery are recommended for localized lesions [3, 9]. When there is a high risk for the relapse of angiosarcoma, highcapacity radiation therapy above $50 \mathrm{~Gy}$ is recommended [9]. When metastatic, the primary treatment is cytotoxic chemotherapy, with the main drugs being doxorubicin, ifosfamide, and taxanes [14]. When a patient has a poor status or is elderly, monotherapy with a taxane-class drug is recommended [15]. The 5-year survival rate for angiosarcoma is as low as $35 \%$. A poor prognosis is predicted for factors such as the primary site of the liver, a performance above 2 on the ECOG scale, and the existence of metastatic lesions at the time of diagnosis [10].

\section{CONCLUSION}

Angiosarcoma should be considered in the differential diagnosis of advanced-aged people presenting with hydropneumothorax and cystic lung lesions. Scalp lesions should be searched in the presentation of pneumothorax in angiosarcoma. Immunohistochemistry provides an indicator for the diagnosis of malignant pleural effusion in angiosarcoma.

\section{CONFLICT OF INTEREST}

The authors confirm that this article content has no conflict of interest.

\section{ACKNOWLEDGEMENTS}

Thanks to Ms. Haesoo Chang for the support of English revision. 
Table 1. Cases of angiosarcoma with spontaneous pneumothorax reported since 1978 .

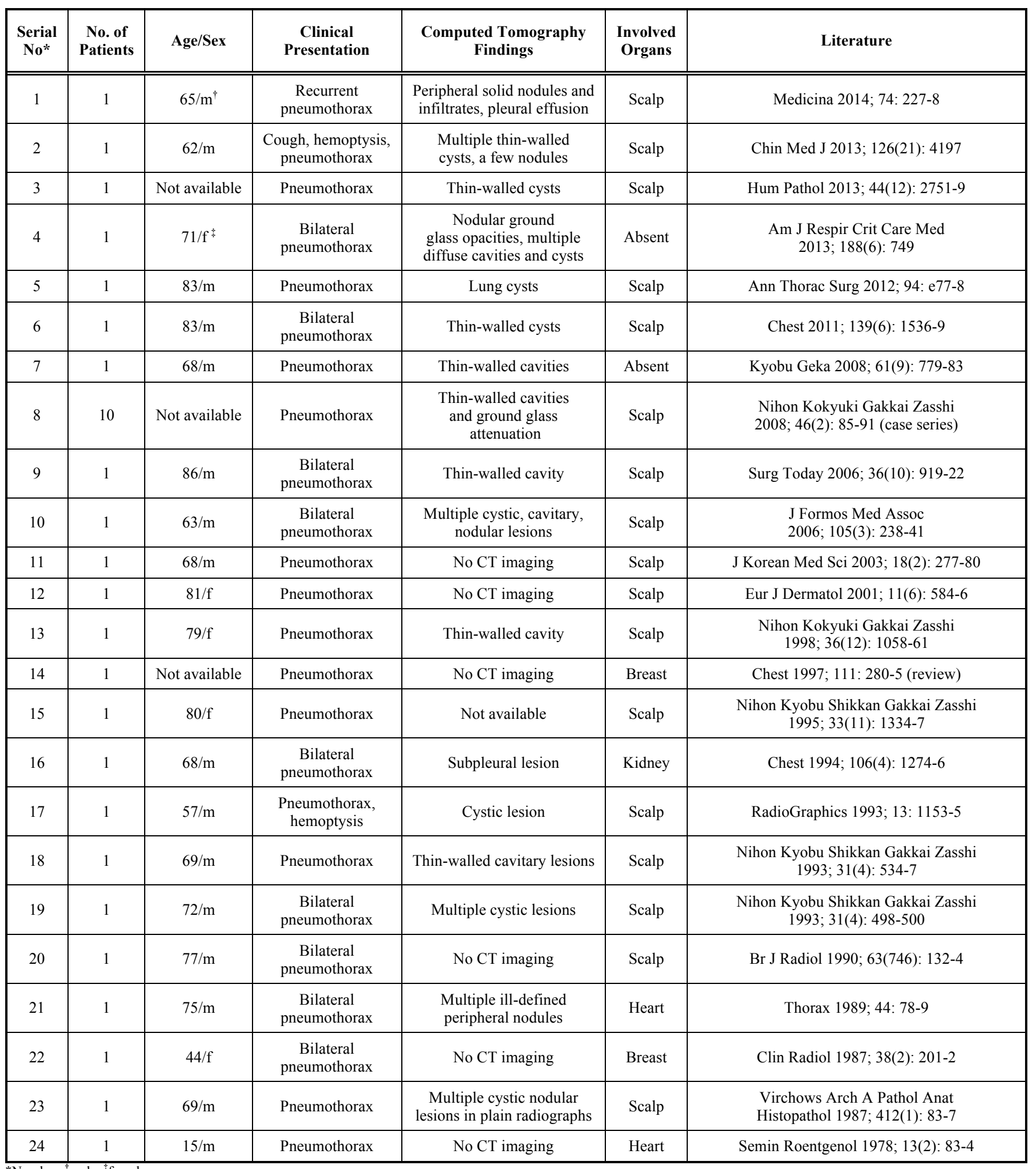

\section{REFERENCES}

[1] Banks-Davis HJ. Haemmorrhagic angiosarcoma of upper jaw. Proc R Soc Med 1923; 16 (Laryngol Sect): 49.

[2] Bear PA, Moodie DS. Malignant primary cardiac tumors: The Cleveland Clinic experience, 1956 to 1986. Chest 1987; 92: 860-2.

[3] Ito Y, Kojiro M, Nakashima $\mathrm{T}$, et al. Pathomorphologic characteristics of 102 cases of thorotrast-related hepatocellular carcinoma, cholangiocarcinoma, and hepatic angiosarcoma. Cancer 1988; 62: 1153-62.

[4] Chen W, Shih CS, Wang YT, Tseng GC, Hsu WH. Angiosarcoma with pulmonary metastasis presenting with spontaneous bilateral pneumothorax in an elderly man. J Formos Med Assoc 2006; 105: 238-41. 
[5] Alexiou C, Clelland CA, Robinson D, Morgan WE. Primary angiosarcomas of the chest wall and pleura. Eur J Cardiothorac Surg 1998; 14: 523-6.

[6] Boucher LD, Swanson PE, Stanley MW, et al. Cytology of Angiosarcoma: findings in fourteen fine-needle aspiration biopsy specimens and one pleural fluid specimen. Am J Clin Pathol 2000; 114: 210-9.

[7] Jordan KG, Kwong JS, Flint J, Muller NL. Surgically treated pneumothorax: radiologic and pathologic findings. Chest 1997; 111: $280-5$.

[8] Rouhani P, Fletcher CD, Devesa SS, Toro JR. Cutaneous soft tissue sarcoma incidence patterns in the U.S.: an analysis of 12,114 cases. Cancer 2008; 113: 616-27.

[9] Mark RJ, Poen JC, Tran LM, Fu YS, Juillard GF. Angiosarcoma: a report of 67 patients and a review of the literature. Cancer 1996; 77: 2400-6.

[10] Fayette J, Martin E, Piperno-Neumann S, et al. Angiosarcomas, a heterogeneous group of sarcomas with specific behavior depending on primary site: a retrospective study of 161 cases. Ann Oncol 2007; 18: 2030-6.

[11] De Young BR, Wick MR, Fitzgibbon JF, Sirgi KE, Swanson PE. CD31: an immunospecific marker for endothelial differentiation in human neoplasm. Appl Immunohistochem 1993; 1: 97-100.

[12] Kitagawa M, Tanaka I, Takemura T, Matsubara O, Kasuga T Angiosarcoma of the scalp: report of two cases with fatal pulmonary complications and a review of Japanese autopsy registry data. Virch Arch A 1987; 412(1): 83-7.

[13] Tateishi U, Hasegawa $\mathrm{T}$, Kusumoto $\mathrm{M}$, et al. Metastatic angiosarcoma of the lung: spectrum of $\mathrm{CT}$ findings. Am Roentgenol 2003; 180: 1671-4.

[14] George S, Demetri GD. Systemic treatment of metastatic soft tissue sarcoma. http: //www.uptodate.com/contents/systemic-treatmentof-metastatic-soft-tissue-sarcoma. 2014

[15] Young RJ, Brown NJ, Reed MW, Hughes D, Woll PJ. Angiosarcoma. Lancet Oncol 2010; 11: 983-91.

Received: October 15, 2014

Revised: November 8, 2014

Accepted: November 11, 2014

(C) Chang et al.; Licensee Bentham Open.

This is an open access article licensed under the terms of the Creative Commons Attribution Non-Commercial License (http://creativecommons.org/licenses/by-nc/3.0/) which permits unrestricted, non-commercial use, distribution and reproduction in any medium, provided the work is properly cited. 